\title{
Benign splenic regrowth mistaken as recurrent renal cell carcinoma
}

\author{
Kristen McAlpine MD, Rodney H. Breau MD MSc
}

— Cite as: CMAJ 2019 December 9;191:E1355-7. doi: 10.1503/cmaj.191128

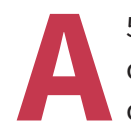

58-year-old woman was seen for follow-up in the urology clinic 18 months after undergoing resection of 2 renal cell carcinomas from her left kidney (partial nephrectomies). The pathology from the resections showed pT1a clear-cell renal cell carcinoma, with negative surgical margins. The patient was clinically well, with no flank pain or hematuria. In addition to her most recent cancer diagnosis, she had previously undergone a right radical nephrectomy 5 years prior for renal cell carcinoma (pT3a clear-cell renal cell carcinoma) and a distal pancreatectomy and splenectomy for an invasive pancreatic ductal adenocarcinoma 1 year prior. A genetic work-up to explain her multiple malignancies at a young age was negative. As part of her routine cancer surveillance, computed tomography (CT) with intravenous contrast showed new, enhancing, nodular tissue abutting the left perirenal fascia adjacent to the site of her previous partial nephrectomy (Figure 1). This was reported as most in keeping with recurrence of renal cell carcinoma. Blood tests (complete blood count, electrolytes, creatinine, calcium, phosphate, albumin, urea) done before the appointment were within normal limits and were all stable compared to earlier results.

The CT images were reviewed by her urologist (R.H.B.), who had performed the partial nephrectomies. Taking into consider-

\section{KEY POINTS}

- Splenosis is the ectopic growth of benign splenic tissue that may be seen after splenectomy or splenic trauma.

- The differential diagnosis of an enhancing soft tissue lesion after intra-abdominal surgery performed for cancer includes local recurrence, metastatic deposit, new primary malignancy, peritoneal carcinomatosis, splenosis, lymphoma and peritoneal mesothelioma.

- The appropriate use and interpretation of heat-damaged red blood cell scans can prevent substantial morbidity and psychologic stress for patients with splenosis initially detected as an enhancing lesion on computed tomography or magnetic resonance imaging.

ation our patient's negative surgical margins, the positioning of the nodules on her CT scan, and her history of multiple abdominal surgeries (including an open splenectomy), we thought it likely that the new soft tissue lesion could represent benign splenic regrowth. Local recurrence of renal cell carcinoma after partial nephrectomy is typically seen as an enhancing lesion in the parenchyma of the kidney at the base of the prior surgical resection, and we did not see this in the CT scan.

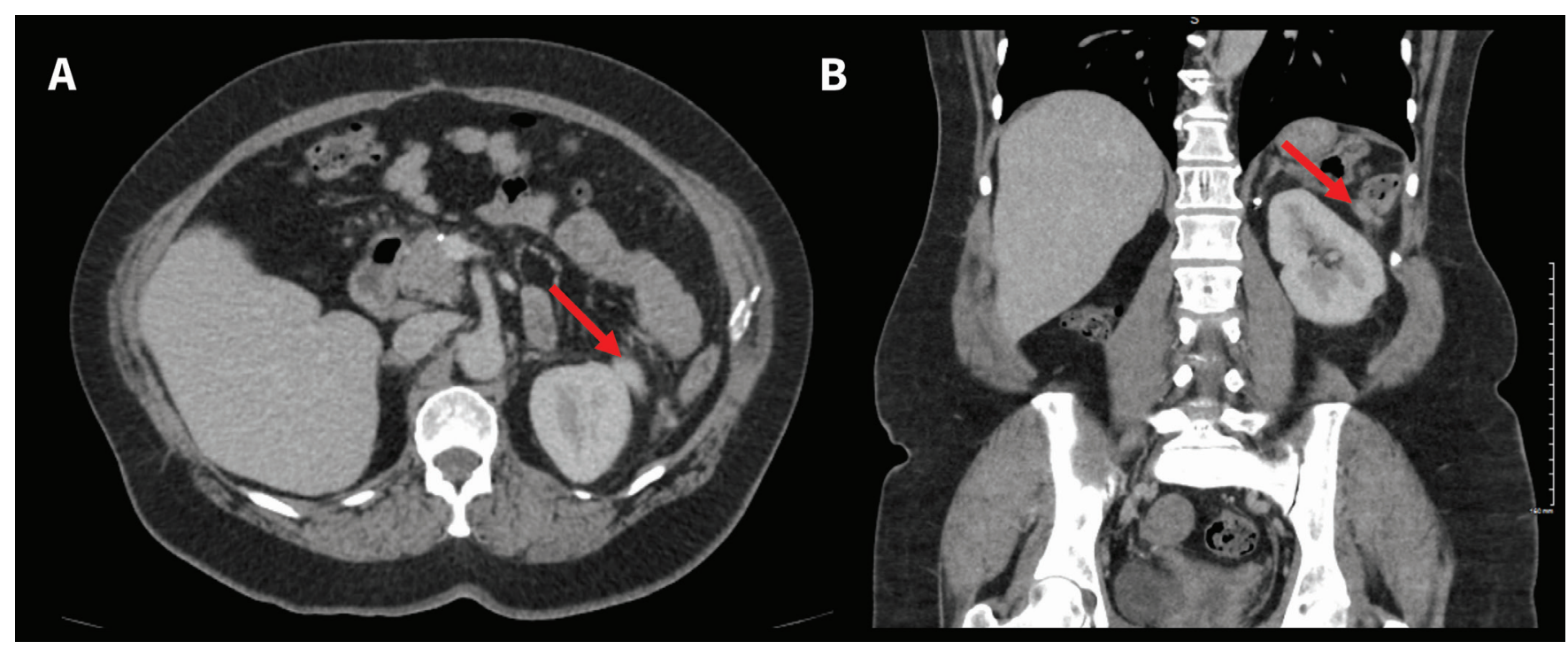

Figure 1: Axial (A) and coronal (B) contrast-enhanced computed tomography images in a 58-year-old woman, with a history of multiple renal cell carcinomas resected from left kidney, showing nodular soft tissue growth (red arrows) abutting the left perirenal fascia adjacent to site of previous partial nephrectomy. 


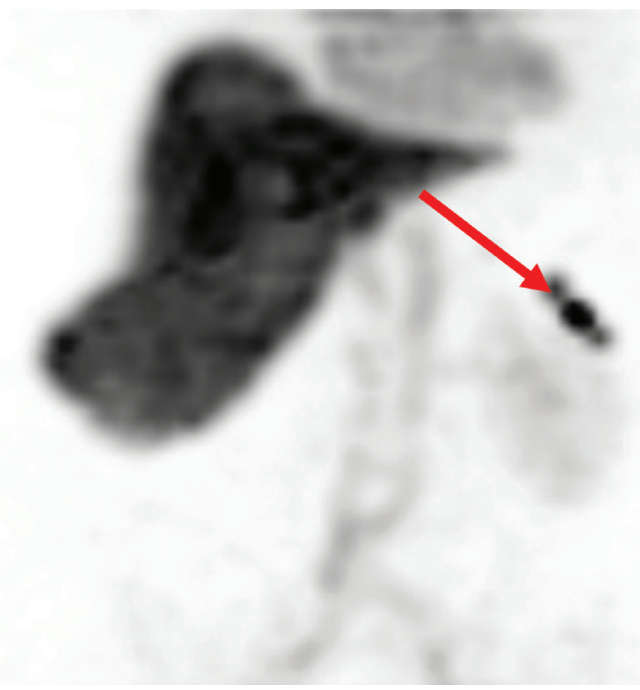

Figure 2: Positive heat-damaged red blood cell scan. Scintigraphy scan showing intense uptake in nodular tissue consistent with splenic tissue (red arrow). Expected hepatic uptake in the background is seen.

Based on experience with similar presentations, we requested a heat-damaged red blood cell (RBC) scan, an imaging technique used to identify ectopic splenic tissue. Radiopharmaceutical technetium-99m heat-damaged RBCs were administered intravenously, and our patient's scan showed an accumulation of activity in the area of interest abutting the left perirenal tissue, confirming the suspected diagnosis of splenosis (Figure 2).

No further investigation or intervention was necessary for the benign splenic regrowth. Our patient continues with routine surveillance after the resected renal cell carcinomas and pancreatic adenocarcinoma. It has been 1 year since the heat-damaged RBC scan, and there continues to be no evidence of cancer recurrence.

\section{Discussion}

Splenosis is the ectopic growth of benign splenic tissue often seen after splenectomy or splenic trauma. ${ }^{1}$ The presumed etiology is spillage of splenic cells at the time of the trauma or surgery to the spleen. These cells then grow over time and can exhibit contrast enhancement on cross-sectional imaging. ${ }^{1}$ Splenosis, which does not require resection or treatment, can mimic concerning processes such as metastatic malignancy, peritoneal carcinomatosis, peritoneal mesothelioma and lymphoma (Box 1). ${ }^{1,2}$

\section{Box 1: Differential diagnosis of enhancing soft tissue} mass after abdominal surgery for cancer ${ }^{1,2}$

- Local recurrence of previously resected malignancy

- Metastatic deposit of renal cell carcinoma or pancreatic adenocarcinoma

- Metastatic deposit of new primary malignancy

- Splenosis

- Peritoneal carcinomatosis

- Peritoneal mesothelioma

- Abdominal lymphoma
An accessory spleen (splenule) is a separate entity from splenosis. Accessory spleens form during embryologic development as a consequence of failed fusion and migration of the splenic buds. They are present in $10 \%-30 \%$ of the population and are typically located adjacent to the spleen (common sites include the splenic hilum, adjacent to the pancreatic tail and along the splenic artery) although various ectopic locations have been reported..$^{3-5}$

Most patients with splenosis or accessory spleens are asymptomatic, and the splenic abnormality is found incidentally on imaging performed for another reason. When symptoms do occur, they are generally a result of the splenic tissue causing blockage of another organ (e.g., bowel obstruction or hydronephrosis) or from bleeding or infarction of the splenic tissue..$^{3,4}$

On conventional imaging of a lesion, specific characteristics may raise suspicion of splenic tissue. On ultrasonography, splenosis or accessory spleens are often round with well-defined margins, uniformly hypoechoic centrally with a hyperechoic rim. ${ }^{6,7}$ On CT, these lesions are homogeneous and hypodense, and have similar contrast enhancement as normal splenic tissue. ${ }^{6}$ Magnetic resonance imaging (MRI) can also be used to assess a lesion suspected to represent splenosis or an accessory spleen. On MRI, splenosis appears dark on $T_{1}$ and $T_{2}$ series and bright on diffusion-weighted imaging. ${ }^{6}$ The contrast enhancement on MRI is similar to what is seen on CT. ${ }^{6}$ Because of its high sensitivity and specificity for splenosis, heat-damaged RBC scanning is considered the gold-standard imaging modality when this diagnosis is contemplated. ${ }^{8}$

Heat-damaged RBC scans are more specific than MRI studies for assessing splenosis. ${ }^{9}$ Before the test, a patient's blood is drawn. Red blood cells are labelled with technetium-99m and heated with a specific protocol to elicit damage before being infused back into the patient. ${ }^{9}$ The test relies on the normal function of the spleen to filter and destroy damaged RBCs. Thirty minutes after the tracer is infused, the patient undergoes imaging. If splenic tissue is present, the heat-damaged RBCs will accumulate in this area and the tracer will be detected on imaging.

The ability to differentiate splenosis from growing malignant lesions is important. For our patient, confidence in the diagnosis of splenosis prevented the risk of invasive testing and the anxiety that goes along with uncertainty. Still, there are limitations to this technology. Use of radiotracers and scintigraphy requires the institutional expertise to produce reliable results. Imprecise technique may result in false-negative results. ${ }^{10}$ Thus, these scans are not available in many centres and may require referral to tertiary care facilities.

\section{References}

1. Tandon YK, Coppa CP, Purysko AS. Splenosis: a great mimicker of neoplastic disease. Abdom Radiol (NY) 2018;43:3054-9.

2. Rizzo S, Monfardini L, Belmonte M, et al. Benign splenosis mimicking peritoneal seeding in a bladder cancer patient: a case report. Cases J 2009;2:9294. doi: 10.1186/1757-1626-2-9294

3. Burke C, Kato K, Chow B. Infarcted splenule. Appl Radiol 2015;44:44-5.

4. Landmann A, Johnson JJ, Webb KM, et al. Accessory spleen presenting as acute abdomen: a case report and operative management. J Pediatr Surg Case Rep 2016;12:9-10. 
5. Porwal R, Singh A, Jain P. Retroperitoneal accessory spleen presented as metastatic suprarenal tumour - a diagnostic dilemma. J Clin Diagn Res 2015;9: PD07-08.

6. Diop AD, Fontarensky M, Montoriol PF, et al. CT imaging of peritoneal carcinomatosis and its mimics. Diagn Interv Imaging 2014;95:861-72.

7. Zugail AS, Ahallal Y, Comperat E-M, et al. Splenorenal fusion mimicking renal cancer: one case report and literature review. Urol Ann 2019;11:211-13.

8. Ferrer Marrero TM, Prieto-Centurion V, Jaffe HA. Thoracic splenosis: History is the key. Respir Med Case Rep 2017;22:251-3.

9. MacDonald A, Burrell S. Infrequently performed studies in nuclear medicine: part 1. J Nucl Med Technol 2008;36:132-43, quiz 145.

10. ACR-SPR practice parameter for the performance of liver and spleen scintigraphy. Reston (VA): American College of Radiology 2015;1076 (Resolution 46):1-8.

\section{Competing interests: None declared.}

This article has been peer reviewed.

The authors have obtained patient consent.

Affiliations: Division of Urology (McAlpine, Breau); The Ottawa Hospital Research Institute (Breau), University of Ottawa, Ottawa, Ont.

Contributors: Both authors wrote the article, gave final approval of the version to be published and agreed to be accountable for all aspects of the work.

Correspondence to: Rodney H. Breau, rbreau@toh.ca 